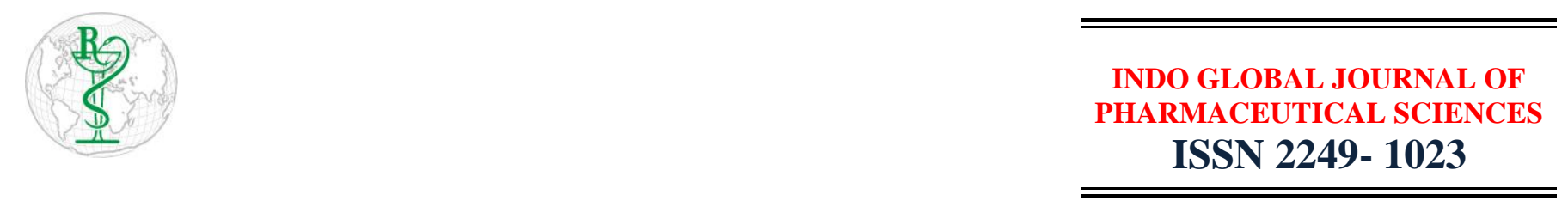

\title{
Recent Advancements in the Treatment of Rheumatoid Arthritis- A Review
}

\begin{abstract}
Received:
01.03.2019

Accepted:

25.03.2019

Keywords

Rheumatoid

arthritis,

Immunosuppress ants, Sarilumab.
\end{abstract}

\author{
Lovepreet Kaur ${ }^{* 1}$, Pooja Sharma ${ }^{1,2}$, Dinesh Kumar ${ }^{1}$ \\ ${ }^{1}$ Sri Sai College of Pharmacy, Manawala, Amritsar-143115, Punjab, India \\ ${ }^{2}$ Department of Pharmaceutical Sciences and Drug Research, Punjabi University Patiala, Punjab, India
}

Address for Correspondence: Lovepreet Kaur; lovepreetkaur1918@gmail.com

\begin{abstract}
Rheumatoid arthritis (RA) is an autoimmune disorder affects the joint inflammation due to synovial proliferation and damage of the articular cartilage in the joints. According to the WHO report (2017), 1.3 million people suffer with RA worldwide. Immunosuppressants, 5-amino salicylic acids, TNF alpha inhibitors, Interleukin -1 antagonists, and corticosteroids are treatment approaches to decrease the severity of the disease. Therapies for rheumatoid arthritis (RA) continue to increases promptly. These traditional treatment methodologies only produce symptomatic relief and are not capable to cure the disease. The purpose of this article is to discuss new treatment options, containing biosimilars, as well as novel agents inhibiting IL-6 and Janus kinase. Sarilumab is the latest biologic for the treatment of RA, approved by the U.S. Food and Drug Administration (FDA) in 2017. It is a human monoclonal antibody consuming higher affinity for the alpha subunit of the interleukin6 (IL-6) receptor. Other drugs that are presently being studied include the IL-6 cytokine blocker sarikumab, the small targeted molecule filgotinib, and many new biosimilars. New non-biologic DMARDs such as PI3Ks inhibitors Phosphoinositide 3-kinases, MMPs inhibitors, matrix metalloproteinases, Glycosidase inhibitors and cathepsin inhibitors are the other novel treatment methods used in the RA. With the discovery of new pathways and therapeutic targets, prospective novel and targeted therapeutic agents are developed that demonstrates their better efficacy in the treatment of RA. () 2019 iGlobal Research and Publishing Foundation. All rights reserved.
\end{abstract}

Cite this article as: Kaur, L.; Sharma, P.; Kumar, D. Recent Advancements in the Treatment of Rheumatoid Arthritis- A Review. Indo Global J. Pharm. Sci., 2019; 9(2Suppl.): $128 . \quad$ DOI: http://doi.org/10.35652/IGJPS.2019.92S26 .

Indo Global Journal of Pharmaceutical Sciences( ISSN 2249 1023; CODEN- IGJPAI; NLM ID: 101610675) indexed and abstracted in CrossRef (DOI Enabling), UGC CARE Journal List, EMBASE(Elsevier), National Library of Medicine (NLM) Catalog, ResearchGate, Publons, CAS (ACS), Index Copernicus, Google Scholar and many more. For further details, visit http://iglobaljournal.com

This is a special issue as an outcome of 'RAPSCON-2019' sponsored by APTI and organized by Sri Sai College of Pharmacy, Manawala, Amritsar, Punjab, India. Relaxation offered in journal format. 